Original

\title{
Linear reciprocal interaction between dental caries and salivary characteristics
}

\author{
Naser Asl Aminabadi1), Ebrahim Najafpour1), Zahra Razavi Rohani1), \\ Alireza Sighari Deljavan'), Morteza Ghojazadeh²), and Zahra Jamali3) \\ 1)Department of Pediatric Dentistry, Faculty of Dentistry, Tabriz University of Medical Science, Tabriz, Iran \\ 2)Department of Medical Physiology, Tabriz University of Medical Science, Tabriz, Iran \\ 3)Department of Oral Science, Faculty of Dentistry, Tabriz University of Medical Science, Tabriz, Iran
}

(Received August 6, 2013; Accepted November 1, 2013)

\begin{abstract}
Carious tooth surfaces can alter saliva in various ways. We investigated whether salivary parameters were affected by elimination of existing active dental caries in 99 children (age 6-12 years) with more than five carious tooth surfaces. Unstimulated saliva samples were obtained from each child, and salivary characteristics were evaluated. One month after caries treatment that eliminated all existing dental caries, saliva sampling and analysis were repeated. Saliva viscosity significantly decreased $(P=$ $0.04)$, while $\mathrm{pH}$ and saliva buffering capacity significantly increased $(P<0.001)$. There was no significant difference in unstimulated salivary production at the start of the study and 1 month after caries elimination $(P>0.05)$. The relationship between dental caries and salivary condition is reciprocal. Treatment of existing dental caries can prevent future caries by improving saliva quality. (J Oral Sci 55, 337-342, 2013)
\end{abstract}

Keywords: dental caries; saliva; tooth remineralization.

\section{Introduction}

Quality and quantity of saliva are important determinants of dental health. Human saliva not only lubricates oral

Correspondence to Dr. Alireza Sighari Deljavan, Department of Pediatric Dentistry, Faculty of Dentistry, Tabriz University of Medical Science, Daneshgah St, Golgasht St, 51665, Tabriz, Iran Fax: +98-4113346977

E-mail: Alireza_Sigharydeljavan@yahoo.com

doi.org/10.2334/josnusd.55.337

DN/JST.JSTAGE/josnusd/55.337 tissues, making oral functions such as speaking, eating, and swallowing possible, it also protects teeth and oral mucosal surfaces in various ways. Stimulation of saliva results in a flushing effect that clears oral debris and noxious agents, dilutes and eliminates sugars and other substances, increases buffering capacity, and balances demineralization/remineralization and antimicrobial activity (1). These protective characteristics of saliva are due to properties such as flow rate, viscosity, $\mathrm{pH}$, buffering capacity, and the concentrations of various components (2). Therefore, alterations in saliva quantity or quality can contribute to development of dental caries.

The relationship of salivary characteristics, including flow rate, viscosity, $\mathrm{pH}$, and buffering capacity, to dental caries has been investigated. Previous studies found a significant direct relationship between saliva viscosity and number of decayed, missing, and filled teeth (3). The increase in cariogenic activity due to viscous saliva is attributed to reduced flow rate and clearance capacity (4), decreased buffering capacity (5), and increased glucose retention time (6). In addition, salivary flow rate is significantly lower in caries-active children than in caries-free individuals $(2,7)$. Both $\mathrm{pH}$ and buffering capacity are directly related to salivary viscosity and flow rate; therefore, viscous saliva and the consequent lower flow rate likely lead to lower $\mathrm{pH}$ and buffering capacity (8).

Surface irregularities caused by dental caries provide a more retentive site for dental plaque and prevent adequate plaque removal by the clearance mechanism of saliva and oral hygiene practices (9). Moreover, rough carious surfaces and increased plaque accumulation enhance colonization of Streptococcus mutans and shelter the 
bacteria from the flushing action of saliva (10). These retentive surface areas also allow filamentous bacteria such as lactobacilli (which have poor adhesion characteristics) to become established in lesions (9). Dental caries also prevents carbohydrate clearance, thereby allowing longer contact time with dental plaque, which results in a marked reduction in the $\mathrm{pH}$ of saliva (10). Therefore, carious surfaces, in turn, likely alter conditions in the oral cavity by increasing bacterial adherence, favoring plaque retention, decreasing carbohydrate clearance, and increasing acid production.

Present evidence suggests that dental caries adversely affects the quality and quantity of saliva, which results in a vicious cycle by which caries and deficient saliva worsen the effects of the other. Thus, we investigated whether salivary characteristics, including viscosity, flow rate, $\mathrm{pH}$, and buffering capacity, were affected by eliminating existing active dental caries. We expected to detect a proportional increase in salivary flow rate, $\mathrm{pH}$, and buffering capacity, as well as decrease in viscosity, after eliminating existing active dental caries.

\section{Study design}

\section{Materials and Methods}

This randomized controlled study was approved by the Committee for Ethics in Research, Tabriz University of Medical Sciences (\#6352, 2012).

\section{Study population}

A total of 99 children were selected from those who sought treatment at the Department of Pediatric Dentistry, Tabriz University of Medical Sciences, during the period from September to November 2012. The children were admitted for routine dental treatments and were examined by a postgraduate student under the supervision of a pediatric dentist. A comprehensive medical and dental history was taken, and a treatment plan was established for each patient. Caries-active children with at least five decayed tooth surfaces were selected if they satisfied the following inclusion criteria: no systemic or local conditions affecting saliva quality and quantity, no use of medication affecting saliva quality or quantity during the previous 6 months (7), and no current orthodontic therapy.

In this study, change in $\mathrm{pH}$ was the primary outcome, and according to the mean difference obtained in a pilot study $(0.35 \pm 0.08)$, with $\alpha=0.05$, power $=80 \%$, and a 0.034 difference, the sample size was calculated to be 90, which was increased to 99 to improve study validity. After preliminary selection of 106 children who satisfied the inclusion criteria, 99 participants were randomly selected to participate in the study. The study procedure was explained to the parents, and informed written consent was obtained from the parents of all participants.

\section{Study procedure}

At the baseline visit, the objectives of the study and its methodology were thoroughly explained to the parents, who were then interviewed to obtain a detailed medical history of their children. Parents were asked to inform researchers of any medications taken by their children during the study period. Informed written consent was obtained from the parents before the study. For each participant, the number of decayed tooth surfaces was recorded according to the criteria established by the World Health Organization (2), and the Silness and Loe plaque index (PI) was assessed (11).

Unstimulated whole saliva was collected, as it is more sensitive for detecting salivary characteristics (12). After saliva sampling, appointments were scheduled to treat existing dental caries, and the children were asked to continue their previous routine oral hygiene practices. At the initial and subsequent appointments, all carious teeth were restored with amalgam or composite. Pulp treatment and extraction were done as indicated.

One month after completion of restorative dental treatment, the patients were recalled for a follow-up visit, when second salivary samples were taken. Before both samplings, participants were asked to avoid eating, drinking, and brushing for at least for $2 \mathrm{~h}$. To avoid the confounding effect of circadian cycle on salivary flow rate, all saliva samples were obtained between $10 \mathrm{AM}$ and 11 AM. Flow rate, viscosity, buffering capacity, and $\mathrm{pH}$ were evaluated in each saliva sample.

Saliva flow rate was estimated by asking children to spit into pre-weighed plastic cylinders for $5 \mathrm{~min}$. The cylinders (containing saliva) were then weighed, and flow rate was calculated in $\mathrm{g} / \mathrm{min}$ which is approximately equivalent to $\mathrm{mL} / \mathrm{min}$ (13). Buffering capacity of saliva was estimated using Ericsson's method, i.e., 1 $\mathrm{mL}$ of saliva was added to $3 \mathrm{~mL}$ of $5 \mathrm{mmol} / \mathrm{L} \mathrm{HCl}$. The mixture was vigorously shaken, after which the stopper was removed to eliminate carbon dioxide. The sample was allowed to stand for $10 \mathrm{~min}$, and the final $\mathrm{pH}$ was measured with a digital $\mathrm{pH}$ meter. Salivary buffering capacity was then scored as follows (14): $0, \mathrm{pH}>6.0 ; 1$, $4.5<\mathrm{pH}<5.5$; and $2, \mathrm{pH}<4.0$.

Saliva viscosity was estimated using a Brookfield rotational viscometer (15), and saliva $\mathrm{pH}$ was measured by using a digital $\mathrm{pH}$ meter (16).

To encourage active participation of parents and children, all services were provided free of charge, and the 
Table 1 Salivary flow rate, viscosity, $\mathrm{pH}$, and buffering capacity before and 1 month after caries treatment*

\begin{tabular}{lcl}
\hline & Before & \multicolumn{1}{c}{ After } \\
\hline Age $(\mathrm{y})$ & $6.75 \pm 2.27(6-12)$ & \\
No. of caries surfaces & $14.51 \pm 2.25(5-70)$ & \\
Flow rate & $2.86 \pm 1.20(1-5)$ & $2.86 \pm 1.16(1-5)$ \\
$\mathrm{pH}$ & $6.99 \pm 0.56(5.34-7.67)$ & $7.40 \pm 0.33(6.70-8)$ \\
Buffering & $5.10 \pm 0.34(4.17-5.52)$ & $5.40 \pm 0.35(4.46-5.93)$ \\
Viscosity & $2.95 \pm 0.86(2.12-6.37)$ & $2.85 \pm 0.85(2.08-6.40)$ \\
\hline
\end{tabular}

*Data are mean \pm standard deviation (minimum-maximum)

Table 2 Salivary characteristics before and after treatment of active dental caries

\begin{tabular}{lccr}
\hline Variables & Mean difference & $t$ & $P$ value \\
\hline Flow rate & $0.00 \pm 0.05$ & & \\
pH & $0.41 \pm 0.08$ & 4.74 & $<0.001$ \\
Buffering capacity & $0.29 \pm 0.05$ & 5.15 & $<0.001$ \\
Viscosity & $0.10 \pm 0.04$ & 2.07 & 0.046 \\
\hline
\end{tabular}

children were given prizes at the end of each session. The participants' parents signed a written consent form, and the study protocol was approved by the Ethics Committee of Tabriz University of Medical Sciences (Reference number 7523).

\section{Statistical analysis}

The data were analyzed using the SPSS software package (version 17; SPSS Inc., Chicago, IL, USA). Descriptive statistics, including means and standard deviations, were calculated for all variables. The main statistical test for addressing the research question was the paired sample $t$-test, which was used to compare data before and after the intervention. Correlations between variables were assessed using the Pearson correlation coefficient test. A $P$ value $<0.05$ was considered to indicate statistical significance.

\section{Results}

The study participants were 99 healthy children (39 [39.4\%] boys and 60 [60.6\%] girls; mean age, $6.75 \pm$ 2.27 years). The mean number of carious surfaces was 14.51 (range, 5-70) at the beginning of the study and 0 at the end of the treatment sessions. The mean plaque index was $72.22 \pm 14.24$ at the study start and $34.364 \pm 18.78$ at the 1 -month recall visit $(P<0.001)$.

No significant difference was found in unstimulated salivary flow rate at the start of the study and 1 month after caries treatment. Mean flow rate was similar before and after the intervention.

As compared with baseline, salivary $\mathrm{pH}$ was signifi-
Table 3 Pearson correlations between number of carious tooth surfaces and $\mathrm{pH}$, buffering capacity, and viscosity

\begin{tabular}{lcc}
\hline Variables & Pearson correlation & $P$ value \\
\hline $\mathrm{pH}$ & 0.34 & 0.025 \\
Buffering capacity & 0.33 & 0.029 \\
Viscosity & 0.44 & 0.005 \\
\hline
\end{tabular}

cantly higher at the end of the treatment sessions: mean $\mathrm{pH}$ increased from $6.99 \pm 0.56$ to $7.40 \pm 0.33$ at the second sampling $(P<0.001)$.

Salivary buffering capacity significantly increased, from $5.10 \pm 0.34$ at baseline to $5.40 \pm 0.35$ after treatment $(P<0.001)$.

Mean viscosity significantly decreased, from $2.95 \pm$ 0.86 to $2.85 \pm 0.85(P=0.04$; Tables 1,2$)$.

The Pearson correlation test revealed that number of carious surfaces was significantly positively correlated with salivary $\mathrm{pH}(P=0.025)$ and buffering capacity $(P=0.029)$ and significantly inversely correlated with viscosity $(P=0.005$; Table 3$)$ (Figs. 1-3).

\section{Discussion}

We investigated whether dental caries has a reciprocal impact on salivary characteristics, which in turn influence the development of dental caries. A number of studies have examined the means by which saliva protects against dental caries. However, dental caries is a complex phenomenon that is mediated by a combination of many overlapping interactions, which must be considered in any assessment of the effects of human saliva on dental caries. Therefore, it remains unclear if dental caries has a reciprocal relationship with salivary composition. There appears to be little evidence regarding the effect of dental caries on salivary characteristics (17). Carious tooth surfaces may induce intraoral changes, such as increased plaque accumulation, elevated bacterial colonization, reduced carbohydrate clearance, and increased acid production. Therefore, in this study, we investigated 


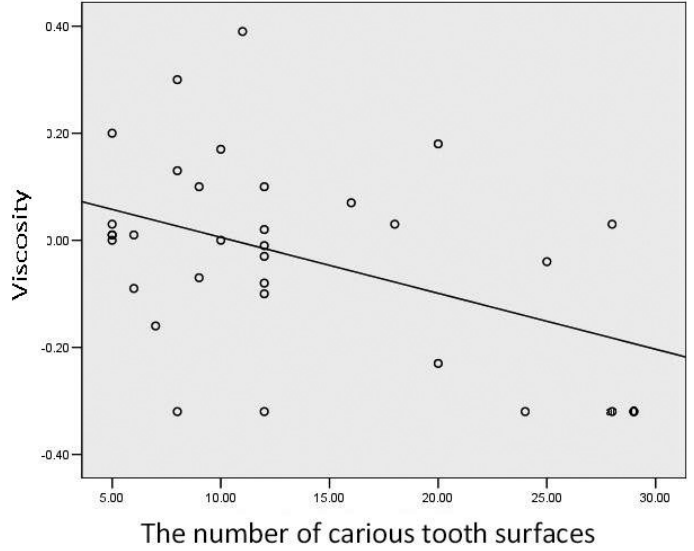

Fig. 1 Correlation between number of carious tooth surfaces and salivary viscosity. The Pearson correlation test showed a significant inverse correlation between viscosity and number of carious tooth surfaces.

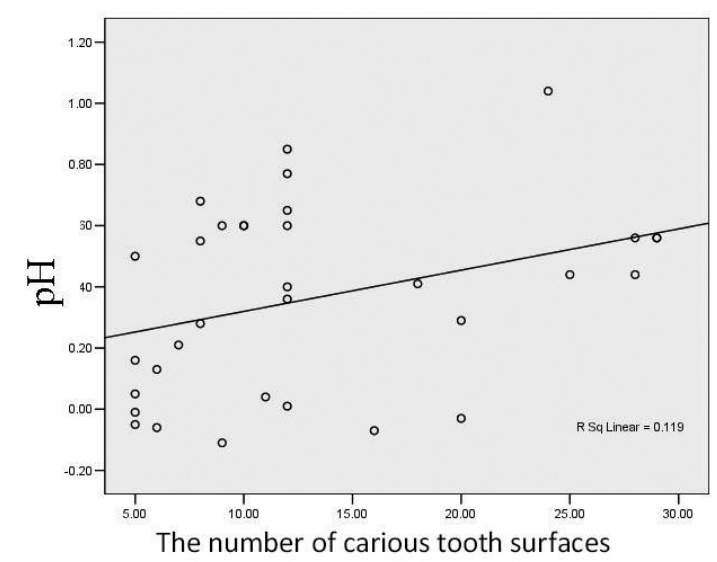

Fig. 2 Correlation between number of carious tooth surfaces and salivary $\mathrm{pH}$. The Pearson correlation test showed a significant positive correlation between salivary $\mathrm{pH}$ and number of carious tooth surfaces.

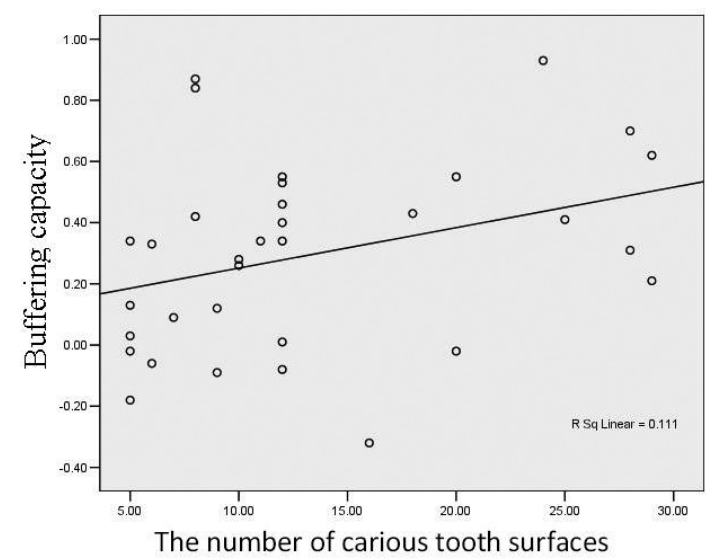

Fig. 3 Correlation between number of carious tooth surfaces and salivary buffering capacity. The Pearson correlation test showed a significant positive correlation between buffering capacity and number of carious tooth surfaces. saliva quality and quantity after eliminating carious lesions.

Interestingly, our results strongly support our hypothesis, namely, elimination of dental carious lesions significantly increased salivary $\mathrm{pH}$ and buffering capacity, and significantly decreased viscosity. However, our results showed no significant effect on salivary flow rate.

Diet has an important role in saliva viscosity. Decayed tooth surfaces and plaque act as reservoirs for carbohydrates and result in higher concentrations of carbohydrates in saliva (due to the slower clearance rate), which increases salivary viscosity (18). Thus, eliminating dental caries likely reduces viscosity by increasing carbohydrate clearance. Moreover, this notion may be due to a decrease in anaerobic bacteria in saliva, as previous studies showed an association between viscosity and number of total salivary anaerobic bacteria (19).

We noted a significant increase in salivary $\mathrm{pH}$. Patients with dental caries have high levels of acidogenic microorganisms, such as $S$. mutans, lactobacilli $(20,21)$, and candida (22) in their oral cavities. The elimination of caries facilitates plaque removal, resulting in less cariogenic bacteria, less carbohydrate accumulation, and ultimately less acid production. Therefore, it is logical to assume that caries removal increases salivary $\mathrm{pH}$. The reduced plaque index seen at the 1-month followup in our patients is consistent with this hypothesis. In many studies, the presence of plaque was attributed to decreased salivary $\mathrm{pH}(16,23)$. Moreover, an association of salivary $\mathrm{pH}$ with number of total anaerobic bacteria in saliva was reported by Ryu et al. (19).

Saliva buffering capacity was significantly higher after dental caries treatment. In a similar recent study, the buffering capacity of a caries-active group was also higher, but the difference was not statistically significant (24). Moreover, Preethi et al. reported that buffering capacity and salivary flow rate were reduced in children with active caries (2). S. mutans count was significantly correlated with buffering capacity of stimulated saliva in children with early childhood caries (17). The buffering capacity of saliva may be exhausted through ongoing production of organic acids by cariogenic bacteria in the oral cavity.

In the present study, we found no significant difference in unstimulated salivary production before and 1 month after treatment of dental caries. This is consistent with the findings of Dodds et al. and Thaweboon et al., who found no difference in salivary flow rates in caries-active versus caries-free young adults $(25,26)$. The results were similar in a study by Lara-Carrillo et al. (27), who showed no 
significant difference in unstimulated salivary flow rate before and 1 month after placement of fixed orthodontic appliances. In addition, resting and stimulated salivary flow rates in caries-active individuals were not significantly higher at a 1-month follow-up examination (24). These differences can be attributed to the fact that salivary flow is controlled by a variety of factors, including food ingestion, sensory stimulation, drugs, smoking, body position, stress, and degree of hydration (28). Dietary factors, daily mood, and intense physical activity, as well as estrogen and thyroid hormone levels - which were not analyzed in this study - may also influence salivary flow rate (29).

The number of treated carious tooth surfaces was significantly positively correlated with salivary $\mathrm{pH}$ and buffering capacity and negatively correlated with salivary viscosity. Thus, it seems that carious surface count has an additive effect on the studied salivary characteristics. Indeed, an increase in retentive sites increases plaque accumulation, leading to higher cariogenic bacteria counts and, ultimately, to higher levels of acid production. Therefore, we conclude that the increases in $\mathrm{pH}$ and buffering capacity and the decrease in viscosity have a linear relationship with the number of eliminated carious tooth surfaces.

Our results highlight the relationship between dental caries and salivary conditions and indicate a reciprocal interaction between dental caries and deficient saliva, i.e., when one deteriorates, so does the other. The present results are further evidence of the need to quickly eliminate all dental caries in a patient, to prevent caries recurrence due to affected salivary conditions.

Our conclusions should be weighed carefully, as the relationship between caries and saliva may be mediated through various intervening factors like sociodemographic variables, oral hygiene practices, and dietary status. Therefore, accurate extrapolation and generalization of the present results will require further investigations that consider oral hygiene and dietary status within a given socioeconomic context, which can affect, positively or negatively, the development of dental caries.

We conclude that saliva is a determinant factor in oral health and that saliva quality can be substantially improved by eliminating dental caries. Our results suggest that early removal of dental caries prevents initiation of a vicious cycle of caries deterioration and helps maintain good oral health in children. Therefore, by eliminating dental caries early, improving saliva quality, and ensuring better oral and dental health, pediatric dentists are at the forefront in helping children.

\section{Acknowledgments}

This study was supported by grants from Tabriz University of Medical Sciences. We appreciate from the assistance of the staff in the Departments of Pediatric Dentistry and Oral Medicine. We are also grateful to the parents and children who participated in the study.

\section{References}

1. Llena-Puy C (2006) The role of saliva in maintaining oral health and as an aid to diagnosis. Med Oral Patol Oral Cir Bucal 11, E449-455.

2. Preethi BP, Reshma D, Anand P (2010) Evaluation of flow rate, $\mathrm{pH}$, buffering capacity, calcium, total proteins and total antioxidant capacity levels of saliva in caries free and caries active children: an in vivo study. Indian J Clin Biochem 25, 425-428.

3. Gopinath VK, Arzreanne AR (2006) Saliva as a diagnostic tool for assessment of dental caries. Arch Orofac Sci 1, 57-59.

4. Dawes C (2008) Salivary flow patterns and the health of hard and soft oral tissues. J Am Dent Assoc 139, Suppl, S18-24.

5. Lenander-Lumikari M, Loimaranta V (2000) Saliva and dental caries. Adv Dent Res 14, 40-47.

6. Negoro M, Nakagaki H, Tsuboi S, Adachi K, Hanaki M, Tanaka D et al. (2000) Oral glucose retention, saliva viscosity and flow rate in 5-year-old children. Arch Oral Biol 45, 10051011.

7. Azevedo LF, Arruda ES, Brancher JA, dos Santos TB, Ignácio SA, Pecharki GD et al. (2005) Salivary parameters, oral health habits, and sochioeconomic aspects as risk factors for dental caries in 12-year children from a private school of the city of Curitiba, Brazil. Rev De Clinical Pesq Odontol 1, 39-44.

8. Pedersen AM, Bardow A, Jensen SB, Nauntofte B (2007) Saliva and gastrointestinal functions of taste, mastication, swallowing and digestion. Oral Dis 8, 117-129.

9. Roberson TM, Heymann HO, Swift EJ (2002) Sturdevant's art and science of operative dentistry. 4th ed, Mosby, St Louis, 64-132.

10. Law V, Seow W, Townsend G (2007) Factors influencing oral colonization of mutans streptococci in young children. Aust Dent J 52, 93-100.

11. Silness J, Loe H (1964) Periodontal disease in pregnancy. II. Correlation between oral hygiene and periodontal condition. Acta Odontol Scand 22, 121-135.

12. Wang SL, Zhao ZT, Li J, Zhu XZ, Dong H, Zhang YG (1998) Investigation of the clinical value of total saliva flow rates. Arch Oral Biol 43, 39-43.

13. Dawes C (1987) Physiological factors affecting salivary flow rate, oral sugar clearance, and the sensation of dry mouth in man. J Dent Res 66, 648-653.

14. Van Nieuw Amerongen A, Bolscher JG, Veerman EC (2004) Salivary proteins: protective and diagnostic value in cariology. Caries Res 38, 247-253.

15. Murineanu R, Ştefãnescu C, Zaharia A, Davidescu C, Popşor S (2011) Evaluation of total unstimulated saliva viscosity 
incomplete edentulous patients. Romanian Journal of Oral Rehabilitation 3, 53-57.

16. Pradhan D, Jain D, Gulati A, Kolhe SJ, Baad R, Rao BS (2012) Effect of the presence of dental plaque on oral sugar clearance and salivary $\mathrm{pH}$ : an in vivo study. J Contemp Dent Pract 13, 753-755.

17. Zhou Q, Bai J, Qin M (2007) Relationship between cariogenic microbe, salivary buffer capacity and early childhood caries. Zhonghua Kou Qiang Yi Xue Za Zhi 42, 581-584.

18. McDonald RE, Avery DR, Dean JA (2011) Dentistry for the child and adolescent. 9th ed, Mosby, St Louis, 177-204.

19. Ryu M, Ueda T, Saito T, Yasui M, Ishihara K, Sakurai K (2010) Oral environmental factors affecting number of microbes in saliva of complete denture wearers. J Oral Rehabil 37, 194-201.

20. Grindefjord M, Dahllof G, Wikner S, Hojer B, Modeer T (1991) Prevalence of mutans streptococci in one-year-old children. Oral Microbiol Immunol 6, 280-283.

21. Nakas E, Zukavonic A (2007) The prevalence of cariogenic salivary micro-organisms in children of various ages. Bosn J Basic Med Sci 7, 166-170.

22. Nikawa H, Yamashiro H, Makihira S, Nishimura M, Egusa H, Furukawa M et al. (2003) In vitro cariogenic potential of Candida albicans. Mycoses 46, 471-478.
23. Kumar A, Hedge R, Dixit U (2011) Role of plaque in the clearance of salivary sucrose and its influence on salivary $\mathrm{pH}$. J Indian Soc Pedod Prev Dent 29, 310-314.

24. Hira PG (2012) Buffering capacity of saliva, salivary flow rates and cortisol levels in patients with active caries. Thesis, University of the Witwatersrand, Johannesburg.

25. Dodds MW, Johnson DA, Mobley CC, Hattaway KM (1997) Parotid saliva protein profiles in caries-free and caries-active adults. Oral Surg Oral Med Oral Pathol Oral Radiol Endod 83, 244-251.

26. Thaweboon S, Thaweboon B, Nakornchai S, Jitmaitree S (2008) Salivary secretory IgA, pH, flow rates, mutans streptococci and Candida in children with rampant caries. Southeast Asian J Trop Med Public Health 39, 893-899.

27. Lara-Carrillo E, Montiel-Bastida NM, Sánchez-Pérez L, Alanís-Tavira J (2010) Effect of orthodontic treatment on saliva, plaque and the levels of Streptococcus mutans and Lactobacillus. Med Oral Patol Oral Cir Bucal 15, 924-929.

28. Dawes C (1993) Considerations in the development of diagnostic tests on saliva. Ann N Y Acad Sci 694, 265-269.

29. Watson RR, McMurray DN, Martin P, Reyes MA (1985) Effect of age, malnutrition and renutrition on free secretory component and IgA in secretions. Am J Clin Nutr 42, 281-288. 